\title{
Synthesis, Structure and Microstructure of $\mathrm{Bi}_{1.5} \mathrm{CuV}_{1.5} \mathrm{O}_{7}$
}

\author{
Math Shivalingayya ${ }^{1}$, R L Raibagkar ${ }^{2 *}$ \\ ${ }^{1}$ Department of Post Graduate Studies and Research in Materials Science, \\ Gulbarga University, Kalaburagi-585106, Karnataka State, India \\ ${ }^{2}$ Department of Post Graduate Studies and Research in Applied Electronics, \\ Gulbarga University, Kalaburagi-585106, Karnataka State, India
}

\begin{abstract}
Copper doped bismuth vanadate with nominal composition $\mathrm{Bi}_{1.5} \mathrm{Cu} \mathrm{V}_{1.5} \mathrm{O}_{7}$ was synthesized using classical solid state reaction method. X-ray analysis conform the formation of monoclinic phase in the as-prepared compound. Different grain size after primary investigation reveals the influence of dopant ions on the domain structure and its microstructure. The phase compositions behaviour was found to be strongly correlated with the partial substitution of heterovalent cation dopant. Energy dispersive spectra confirm the occurrence of stoichiometric elements within the synthesized compounds.
\end{abstract}

Keywords: Bismuth pyrochlore ceramics, Structure. Energy dispersive spectra, Microstructure.

\section{Introduction}

The manufacturing of highly integrated electronic devices for future gadgets, used in telecommunication and mobile communication systems sustained the improvement of modified microwave pyrochlore dielectric ceramics based technology. This has also kept a momentum in synthesizing the novel high frequency dielectric materials for the development of multilayer components and devices operating at wideband microwave frequency range [1]-[2]. Bismuthbased pyrochlore ceramics are such dielectric materials which has low sintering temperature $\left(<900^{\circ} \mathrm{C}\right)$ and exhibit significant dielectric characteristics such as high dielectric constant $\left(\varepsilon_{\mathrm{r}}\right)$ and low tangent loss $(\tan \delta)$, controllable temperature coefficients of $\alpha_{\varepsilon}$ and compatibility with $\mathrm{Ag}$ electrodes which can significantly ease the assembly cost [3][4].

The pyrochlore structure, of general formula $\mathrm{A}_{2} \mathrm{~B}_{2} \mathrm{O}_{7}$, contains a large A cation divalent or trivalent that typically prefer a site having eight coordination number and a smaller tetravalent or pentavalent cation B that typically occurs in octahedral sites [5]-[7]. It has sizeable compositional and structural flexibility, including the opportunity to put together a broad choice of dopant ions. Hence a partial or complete ion replacement, such as $\mathrm{Cu}^{2+}, \mathrm{Mg}^{2+}, \mathrm{Sr}^{2+}, \mathrm{Ce}^{4+}, \mathrm{Zr}^{4+}$ and $\mathrm{Ti}^{4+}$, is normally used to improve the dielectric properties, especially to enhance dielectric constant and adjust temperature coefficient of dielectric constant [8]-[9]. It is well known fact that the structural stability of pyrochlores is generally governed by the radius ratio of $\mathrm{A}$ and $\mathrm{B}$ cations. Furthermore, the role of dopants at specific cationic site plays a very important role in understanding the structureproperty relationship in ceramic compounds.

Hence, we have made an attempt to synthesize a modified bismuth vanadate compound doped with heterovalent copper and in this paper we report its preliminary structure and microstructure.

\section{Experimental}

Modified pyrochlore compound $\mathrm{Bi}_{1.5} \mathrm{CuV}_{1.5} \mathrm{O}_{7}$ (BCV) was prepared using conventional solid-state reaction. $\mathrm{Bi}_{2} \mathrm{O}_{3}, \mathrm{CuO}$ and $\mathrm{V}_{2} \mathrm{O}_{5}$ (All $99.5 \%$ pure) were mixed in an agate mortar for $3 \mathrm{~h}$. The mixture was calcined twice at $650^{\circ} \mathrm{C}$ for $2 \mathrm{~h}$ in air. The calcined powder was milled again for $4 \mathrm{~h}$, sieved and compacted in circular pellets and sintered at $690^{\circ} \mathrm{C}$ for $4 \mathrm{~h}$. The phase composition of each sample was investigated by powder x-ray diffraction (XRD, Philips make, X'pert Pro PANanalytical model) using $N i$-filtered $C u K_{\alpha}(\lambda=1.5406 \AA)$ radiation between $2 \theta=10^{\circ}-80^{\circ}$, with a step size of $0.02^{\circ}$ with a scan step time 0.5 having sampling rate of $5 \mathrm{~s} \mathrm{step}^{-1}$. The XRD pattern was analyzed by the Rietveld method using the UNITCELL program. A pseudo-Voigt function was used to generate the line-shape of the diffraction peaks. The scanning electron micrograph (SEM) image and energy dispersive spectra (EDS) pattern were also obtained for the microstructure and elemental analysis of the polished samples using scanning electron microscope (Carl Zeiss EVO18 EDS Oxford).

\section{Results and Discussion}

X-ray diffraction pattern of the $\mathrm{Bi}_{1.5} \mathrm{CuV}_{1.5} \mathrm{O}_{7}$ revealed the single phase nature of the compound. The powder xrd pattern was indexed based on monoclinic crystal symmetry. In order to clarify the influence of copper ion magnesium substitution in the structure, the lattice parameter and crystal symmetry were determined by Rietveld analysis.

Table 1 summarizes the structural data of $\mathrm{Bi}_{1.5} \mathrm{CuV}_{1.5} \mathrm{O}_{7}$ ceramics. The $\mathrm{Cu}^{2+}$ ion partially occupy both the cationic sites.

Thus, the pyrochlore phase, $\left(\mathrm{Bi}_{1.5} \mathrm{Cu}_{0.5}\right)\left(\mathrm{Cu}_{0.5} \mathrm{~V}_{1.5}\right) \mathrm{O}_{7}$ is formed by the combination of two inter-penetrating networks consisting of $\mathrm{BO}_{6}$ octahedra and $\mathrm{A}_{2} \mathrm{O}$ tetrahedral plane. 


\section{International Journal of Science and Research (IJSR) \\ ISSN (Online): 2319-7064}

Index Copernicus Value (2013): 6.14 | Impact Factor (2014): 5.611

Table 1: Structural data of $\mathrm{Bi}_{15} \mathrm{CuV}_{15} \mathrm{O}_{7}$ ceramics

\begin{tabular}{|c|c|c|c|c|c|}
\hline \multirow{2}{*}{$\begin{array}{c}\text { Ceramic } \\
\text { sample }\end{array}$} & \multicolumn{3}{|c|}{ Lattice parameters $(\AA)$} & $\beta\left(^{\circ}\right)$ & $\begin{array}{c}\text { Cell volume } \\
(\AA)\end{array}$ \\
\cline { 2 - 4 } & $\mathrm{a}$ & $\mathrm{b}$ & $\mathrm{c}$ & & $\left(\AA^{3}\right.$ \\
\hline $\mathrm{BCV}$ & 7.7781 & 5.5317 & 7.6173 & 100.55 & 322.20 \\
\hline
\end{tabular}

The large difference of the ionic radius between $\mathrm{A}$ and $\mathrm{B}$ cations was suggested as the reason for the instability of pyrochlore [10]. Further, the tolerance factor calculations contain more structural information, which gives further insight into the details of the structural stability features in the monoclinic $\mathrm{Bi}_{1.5} \mathrm{CuV}_{1.5} \mathrm{O}_{7}$.

It has been reported that $\mathrm{Bi}^{3+}$ content demonstrates a strong effect on the phase progression in the Bi-based pyrochlores, and the distorted phase is suggested to result from the longrange coupling of the $6 s^{2}$ lone-pair electrons of $\mathrm{Bi}^{3+}$ on the $\mathrm{A}$ site position, which can be affected by the nature of B-site cations [11]. K. Sudheendran et al [12] communicated that broad Raman modes appears due to disordering of $\mathrm{Zn}^{2+}$ and $\mathrm{Nb}^{5+}$ ions at the $\mathrm{B}$-site of the pyrochlore monoclinic $\mathrm{Bi}_{2} \mathrm{Zn}_{2 / 3} \mathrm{Nb}_{4 / 3} \mathrm{O}_{7}$ bulk and thin film. This can be correlated with our monoclinic $\mathrm{Bi}_{1.5} \mathrm{CuV}_{1.5} \mathrm{O}_{7}$ bulk compound leading to pyrochlore phase formation because of change in $\mathrm{Cu}-\mathrm{O}$ and $\mathrm{V}-\mathrm{O}$ binding energy at $2 \theta=28.39^{\circ}$.

The microstructure of the synthesized compound exhibiting elongated dispersed grains is depicted in Figure 1(a) and 2(a). The grain size decreases with $\mathrm{Cu}^{2+}$ substitution and showed a bi-model distribution in the microstructure.
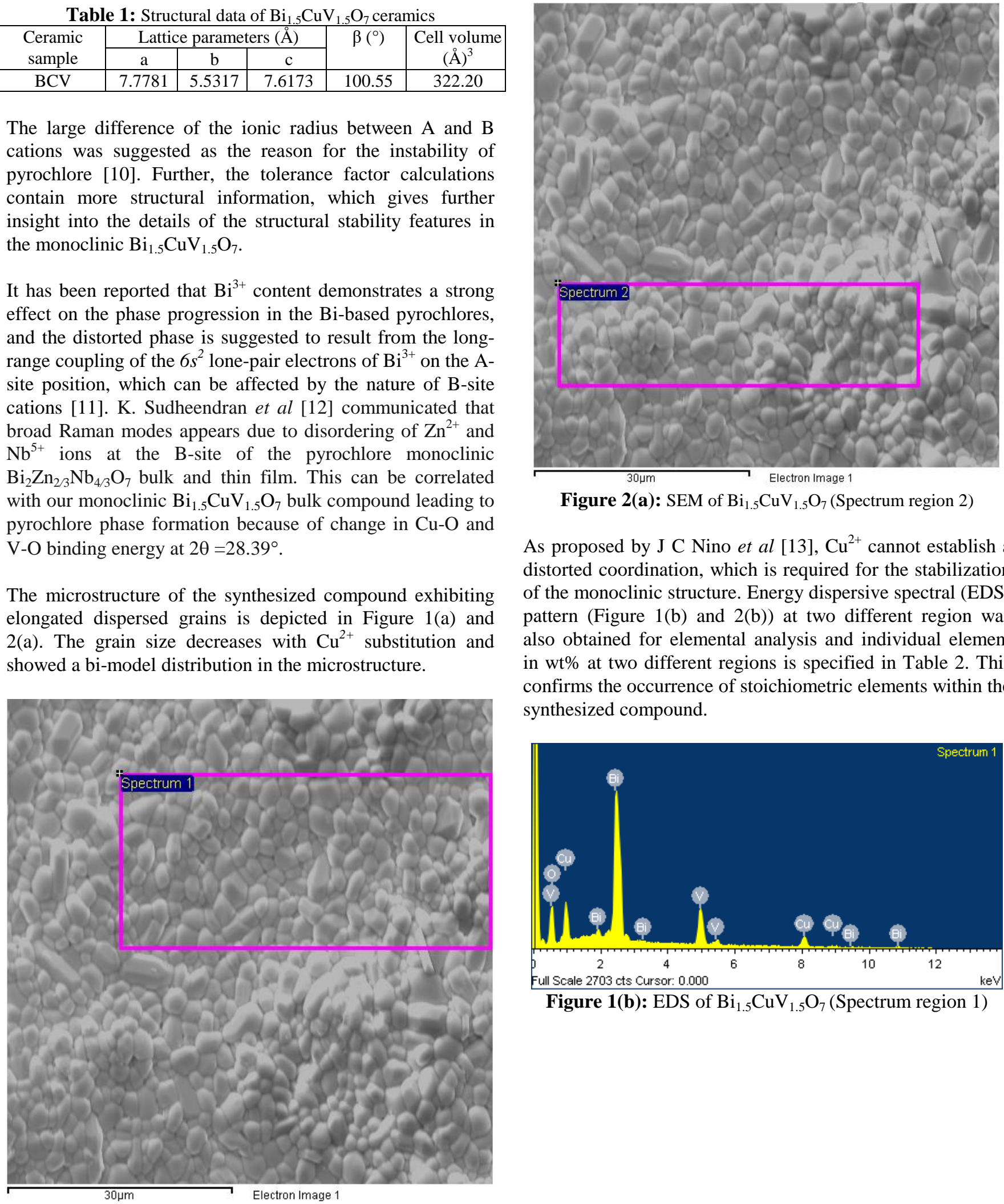

Figure 2(a): $\mathrm{SEM}$ of $\mathrm{Bi}_{1.5} \mathrm{CuV}_{1.5} \mathrm{O}_{7}$ (Spectrum region 2)

As proposed by $\mathrm{J} \mathrm{C}$ Nino et al [13], $\mathrm{Cu}^{2+}$ cannot establish a distorted coordination, which is required for the stabilization of the monoclinic structure. Energy dispersive spectral (EDS) pattern (Figure 1(b) and 2(b)) at two different region was also obtained for elemental analysis and individual element in $w t \%$ at two different regions is specified in Table 2. This confirms the occurrence of stoichiometric elements within the synthesized compound.

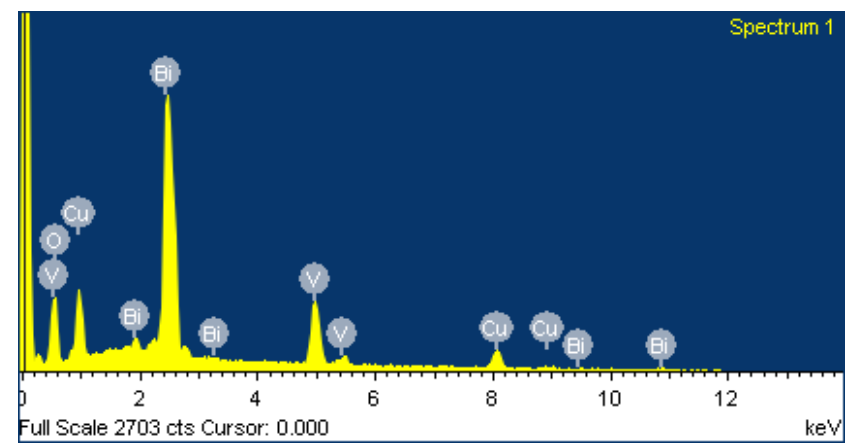

Figure 1(b): EDS of $\mathrm{Bi}_{1.5} \mathrm{CuV}_{1.5} \mathrm{O}_{7}$ (Spectrum region 1)

Figure 1(a): $\mathrm{SEM}$ of $\mathrm{Bi}_{1.5} \mathrm{CuV}_{1.5} \mathrm{O}_{7}$ (Spectrum region 1) 


\section{International Journal of Science and Research (IJSR) \\ ISSN (Online): 2319-7064}

Index Copernicus Value (2013): 6.14 | Impact Factor (2014): 5.611

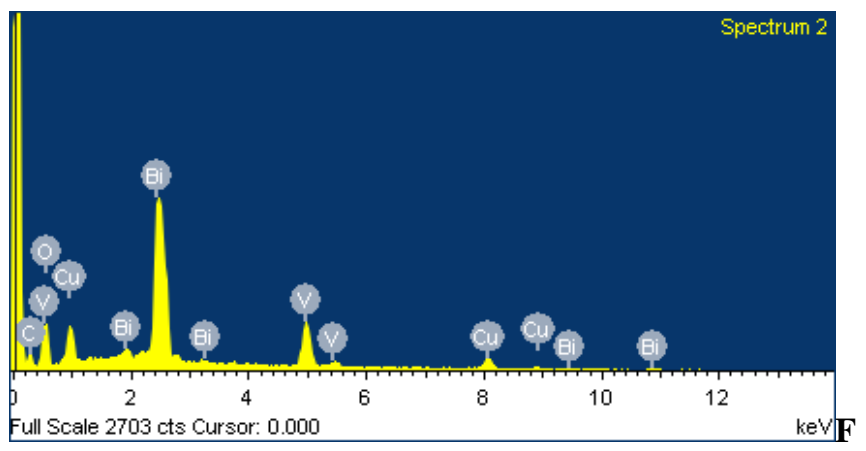

igure 2(b): $\mathrm{EDS}$ of $\mathrm{Bi}_{1.5} \mathrm{CuV}_{1.5} \mathrm{O}_{7}$ (Spectrum region 2)

Table 2: EDS data of $\mathrm{Bi}_{1.5} \mathrm{CuV}_{1.5} \mathrm{O}_{7}$ ceramics

\begin{tabular}{|c|c|c|c|c|}
\hline \multirow{2}{*}{$\begin{array}{c}\text { Spectrum } \\
\text { Region }\end{array}$} & \multicolumn{4}{|c|}{$\mathrm{Wt} \%$} \\
\cline { 2 - 5 } & $\mathrm{O}$ & $\mathrm{V}$ & $\mathrm{Cu}$ & $\mathrm{Bi}$ \\
\hline 1 & 14.28 & 13.29 & 14.31 & 58.12 \\
\hline 2 & 15.60 & 13.85 & 12.54 & 58.00 \\
\hline
\end{tabular}

\section{Acknowledgements}

One of the Authors (MS) thanks the Gulbarga University for providing financial assistance to carry this research work.

\section{References}

[1] C.A. Randall, J.C. Nino, A. Baker, H.-J.Youn, A.Hitomi, R.Thayer, L.F. Edge,T. Sogabe, D.Anderson, T.R.Shrout, S.Trolier-McKinstry and M.T. Lanagan, "Bi-Pyrochlore and zirconolite dielectrics for integrated passive component applications", Am Ceram Soc Bull., 9101-9108, Nov. 2003.

[2] Chon Mun Ping, Tan Kar Ban, Khaw Chwin Chieh, Zulkarnain Zainal and Taufiq-Yap Yun Hin, "Preparation and characterization of new $\mathrm{Bi}_{1.5}$ ${ }_{\mathrm{x}} \mathrm{CuNb}_{1.5+\mathrm{x}} \mathrm{O}_{7+\mathrm{x}}$ pyrochlores", Sol St Sci Tech, 19(1), 175-189, 2011.

[3] Di Zhou, Wen-Bo Li, Li-Xia Pang, Jing Guo, Ze-Ming Qi, Tao Shao, Xi Yao and Clive A. Randall, "Phase evolution and microwave dielectric properties of $\mathrm{xBi}_{2 / 3} \mathrm{MoO}_{4}-(1-\mathrm{x}) \mathrm{BiVO}_{4}(0.0 \leq \mathrm{x} \leq 1.0)$ low temperature firing ceramics", Dalton Trans., 43, 7290-7297, 2014.

[4] Wei-Fang Su, and Shin-Chih Lin, "Interfacial behaviour between $\mathrm{Bi}_{1.5} \mathrm{ZnNb}_{1.5} \mathrm{O}_{7} .0 .02 \mathrm{~V}_{2} \mathrm{O}_{5}$ and $\mathrm{Ag}$ ", J Euro Ceram Soc., 23, 2593-2596, 2003.

[5] Hong Wang, Stanislav Kamba, Meiling Zhang and Xi Yao, Sergey Denisov, Filip Kadlec, and Jan Petzelt, "Microwave and infrared dielectric response of monoclinic bismuth zinc niobate based pyrochlore ceramics with ion substitution in A site", J Appl Phy, 100, 034109, 2006.

[6] Xiaojian Fan, Ruiting Sun, and Xiaoli Wang, "Crystal structures and dielectric properties of $\mathrm{Bi}_{2}\left(\left(\mathrm{Zn}_{1 / 3} \mathrm{Nb}_{2 / 3}\right)_{1 \text { - }}\right.$ $\left.{ }_{\mathrm{x}} \mathrm{Ti}_{\mathrm{x}}\right)_{2} \mathrm{O}_{7}$ ceramics", J. Am. Ceram. Soc., 95 [4] 11971200, 2012.

[7] M. A.Subramanian, G Aravamudan, G.V.S. Rao, "Oxide pyrochlores-A review”, Prog. Sol. St. Chem.,15,55-143, 1983.

[8] V. P. Sirotinkin, and A.A. Bush, "Preparation and dielectric properties of $\mathrm{Bi}_{1.5} \mathrm{MNb}_{1.5} \mathrm{O}_{7}(\mathrm{M}=\mathrm{Cu}, \mathrm{Mg}, \mathrm{Mn}$,
$\mathrm{Ni}, \mathrm{Zn})$ pyrochlore oxides", Inorg. Mater., 39, 974-977, 2003.

[9] X. Wang, H. Wang, and X. Yao, "Structures, phase transformations, and dielectric properties of pyrochlores containing bismuth", J. Am. Cera. Soc., 80, 2745-2748, 1997.

[10] S. S. Lopatin, L.N. Averyanova, and I. N. Belyaev, "Effect of ion radii and the atom electronegativity on the type of crystal-structure of $\mathrm{A}_{2} \mathrm{~B}_{2} \mathrm{O}_{7}$ combination compounds", Zh.Neorg. Khim. 30, 867-872, 1985.

[11] V. Krayzman, I. Levin, and J.C. Woicik, "Local structure of displacively disordered pyrochlore dielectrics", Chem. Mat., 19, 932-936, 2007.

[12] K. Sudheendran, M.K. Singh, M.G. Krishna, and J. K. C. Raju, "Microwave and optical properties of monoclinic $\mathrm{Bi}_{2} \mathrm{Zn}_{2 / 3} \mathrm{Nb}_{4 / 3} \mathrm{O}_{7}$ thin films", Eur. Phys. $J$. Appl. Phys. 58, 10303, 2012.

[13] J.C. Nino, I.M. Reaney, M.T. Lanagan, and C.A. Randall, "Transmission electron microscopy of bismuth based pyrochlore systems", Mat. Lett., 57[2], 414-419, 2002 .

\section{Author Profile}

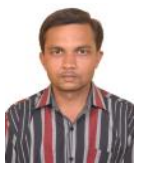

Math Shivalingayya received the M. Sc. in Materials Science Gulbarga University, Kalaburagi (Karnataka State) India in 2012. He is a recipient of 2 gold medals. One gold medal for $1^{\text {st }}$ rank in M.Sc from Gulbarga University and second medal is received from Premier Explosives Limited, Secunderabad for scoring highest marks in High Energy Materials theory paper. Presently, he is pursuing Ph.D in Materials Science on synthesis and characterization of pyrochlores ceramics for LTCC applications.

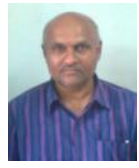

R L Raibagkar received the M.Sc. and Ph. D degrees in Physics from Marathwada University, Aurangabad (Maharashtra State) India in 1989 and 1993, respectively. His research interest includes Electronic ceramics-synthesis, characterization and its applications. He is a Professor of Applied Electronics in the Gulbarga University, Kalaburagi, Karnataka State, India.

\section{Volume 5 Issue 2, February 2016 www.ijsr.net}

